\title{
Correction to: Glioma cells escaped from cytotoxicity of temozolomide and vincristine by communicating with human astrocytes
}

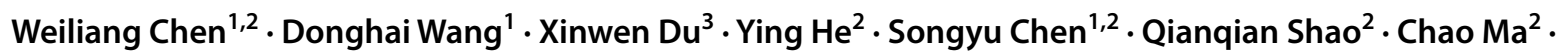
Bin Huang ${ }^{1}$. Anjing Chen ${ }^{1} \cdot$ Peng Zhao ${ }^{1} \cdot$ Xun $\mathrm{Qu}^{2} \cdot$ Xingang $\mathrm{Li}^{1}$

Published online: 24 August 2021

๑) Springer Science+Business Media, LLC, part of Springer Nature 2021

Correction to: Medical Oncology (2015) 32:43

https://doi.org/10.1007/s12032-015-0487-0

The original version of this article unfortunately contained a mistakes in Fig. 3c. The correct Fig. 3c is given below.

The original article can be found online at https://doi.org/10.1007/ s12032-015-0487-0.

Xingang Li

lixg@sdu.edu.cn

1 Department of Neurosurgery, Qilu Hospital of Shandong University and Brain Science Research Institute, Shandong University, Jinan 250012, China

2 Institute of Basic Medical Sciences, Qilu Hospital of Shandong University, Jinan, China

3 Department of Pediatric Surgery, Laizhou People's Hospital, Yantai, China 
(a)

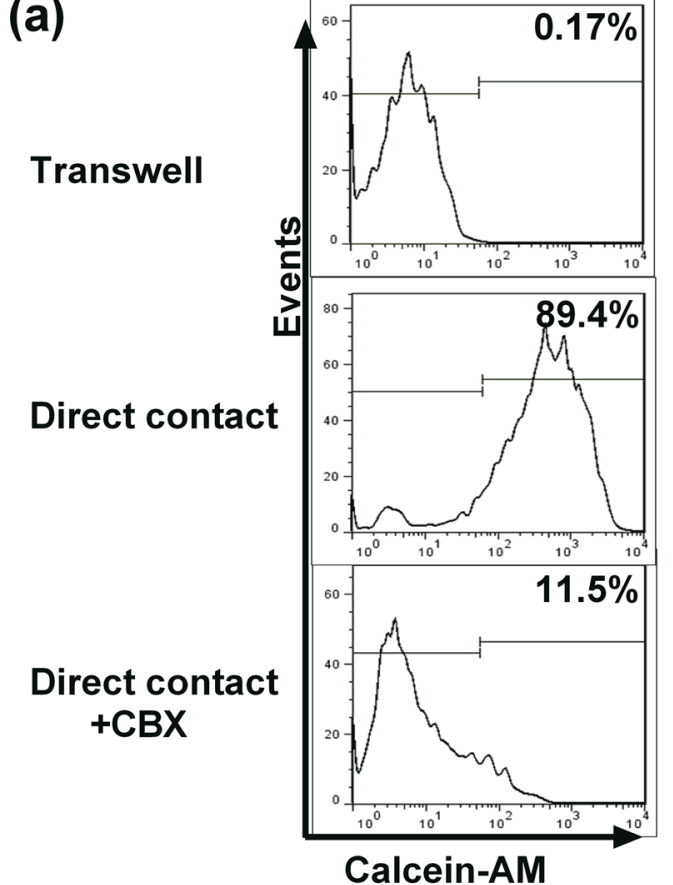

(b)

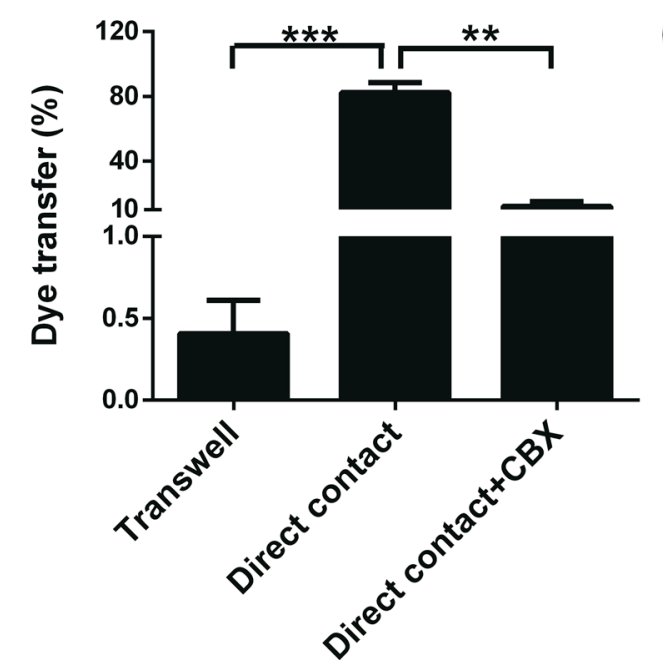

Fig. 3 Gap junctional communication (GJC) between glioma cells and astrocytes is required for protection from apoptosis. a, b Glioma cells and astrocytes formed functional GJCs, as measured through a dye transfer assay. A172 cells labeled with membrane-bound DiIC18 dye and NHA labeled with calcein-AM were co-cultured in different culture systems. After co-culturing for $6 \mathrm{~h}$, the cells were harvested and analyzed by flow cytometry. CBX $(100 \mathrm{lM})$ was used to inhibit GJC. A172 cells were analyzed for calcein-AM fluorescence under

(d)
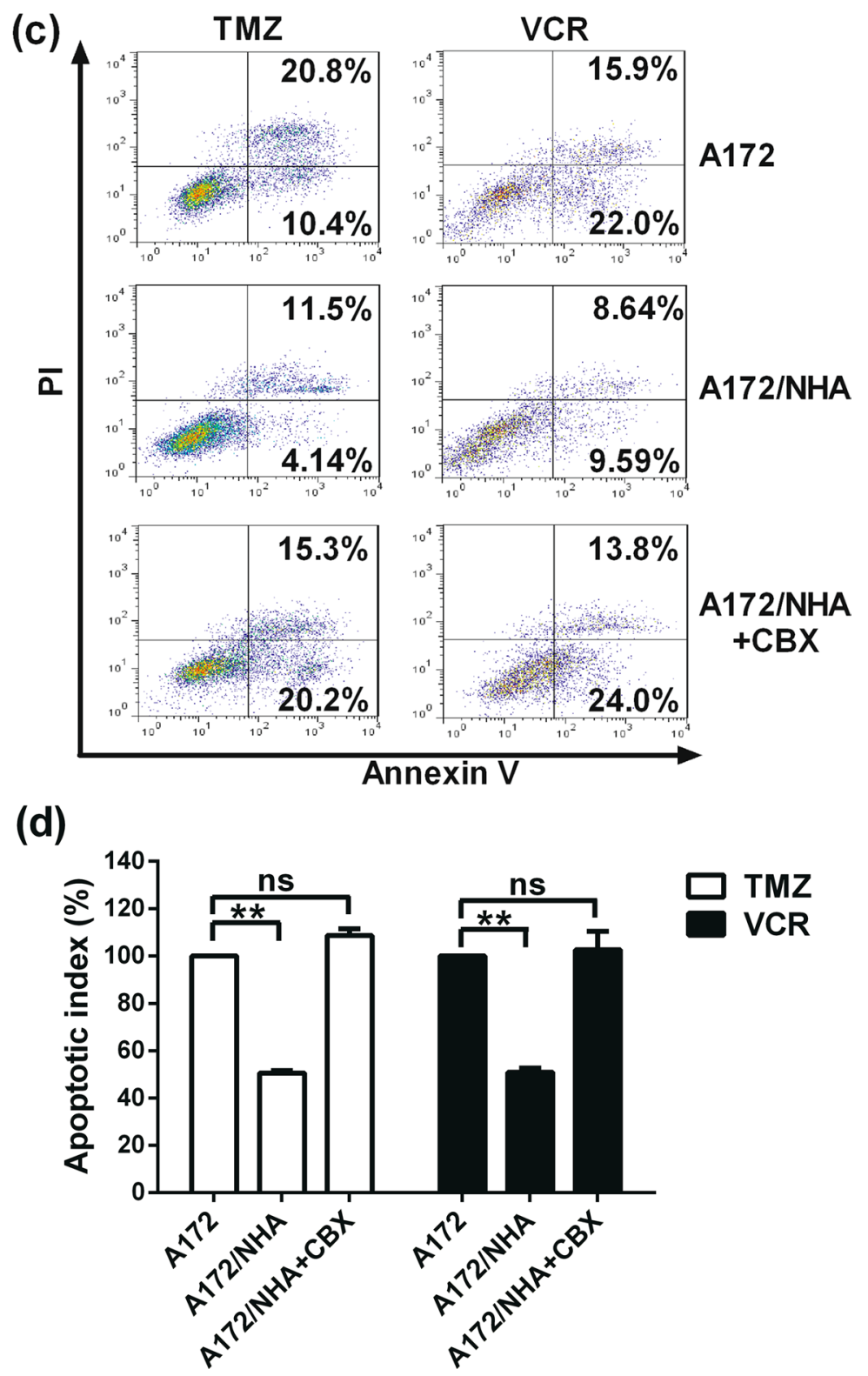

the DiIC18-positive gate (a). The dye transfer was determined by the calcein-positive fraction of DiIC18-positive A172 cells (b). c, d CBX treatment reversed the decrease in apoptosis of glioma cells protected by directly co-cultured astrocytes. When indicated, the direct contact co-cultured NHA and A172 cells were pre-incubated with CBX for $1 \mathrm{~h}$ before TMZ or VCR addition. All data are the mean \pm SD of three independent experiments; $* * p<0.01 ; * * * p<0.001$

Publisher's Note Springer Nature remains neutral with regard to jurisdictional claims in published maps and institutional affiliations. 